\title{
Authors' response to Metzdorf et al
}

We appreciate the contribution to this discussion from Metzdorf et $a l^{1}$, and the efforts made by the company to assess the safety of the Handihaler and Respimat through pooling datasets from randomised controlled trials. We would like reassurance that the pooled analysis of the three 1-year and one 6-month placebocontrolled trials with Spiriva Respimat detailed on the product information website was based on an intention to treat analysis, and involved no reclassification of deaths. This analysis provides essential information for prescribers and should be published. We agree that patient-level data are preferable to pooled population data, but the value of such an analysis is reduced if undertaken on a modified dataset. To date we consider the pharmacokinetic data regarding the comparative safety of tiotropium delivered by Respimat compared with the Handihaler is inconclusive and more work is needed. Based on the different deposition, absorption and physical properties of solutions and dry powders, we do not believe that a difference in systemic absorption and cardiovascular risk between these two would be implausible.

We are not convinced by their interpretation of the 2010 abstract that patients enrolled in the tiotropium trial programme have a comorbidity profile comparable with the general chronic obstructive pulmonary disease (COPD) population, as there are insufficient details provided regarding diagnostic definitions used and no data is presented on the proportion of patients with rhythm disorders. Furthermore, comparison is required with a COPD population of similar severity to that enrolled in the tiotropium clinical trial programme. It is evident that the exclusion of patients with moderate to severe renal impairment, or a recent myocardial infarction, heart failure or rhythm disorder, results in findings that are poorly generalisable to patients with severe COPD. As a result it would be prudent to recommend that tiotropium Handihaler should only be prescribed to the subgroups of patients in whom tiotropium Handihaler has been 
shown to have a favourable efficacy/safety profile, that is, to COPD patients without a recent cardiovascular event or renal comorbidity.

\section{Christine R Jenkins, ${ }^{1}$ Richard Beasley ${ }^{2}$}

${ }^{1}$ The George Institute for Global Health, Sydney, Australia

${ }^{2}$ Medical Research Institute of New Zealand, Wellington, New Zealand

Correspondence to Dr Christine R Jenkins, The George Institute for Global Health, PO Box M201, Missenden Rd, Camperdown, NSW 2050, Australia; christine.jenkins@sydney.edu.au

Competing interests None.

Provenance and peer review Not commissioned; internally peer reviewed.

To cite Jenkins $C R$, Beasley R. Thorax 2013;68:782-783.

Received 5 February 2013

Accepted 6 February 2013

Published Online First 5 March 2013

\section{SLinked}

- http://dx.doi.org/10.1136/thoraxjnl-2013-203228

Thorax 2013;68:782-783.

doi:10.1136/thoraxjnl-2013-203380

\section{REFERENCE}

1 Metzdorf N, Hallman C, Disse B. Thorax editorial by Jenkins and Beasley related to tiotropium Respimat. Thorax 2013;68:782. 